\title{
DESIGNING FOR SELF-REPORTING
}

\author{
Clare GREEN ${ }^{1,2}$ \\ ${ }^{1}$ ISD Rubika, Valenciennes, France \\ ${ }^{2}$ EHESS (Ecole des Hautes Etudes en Sciences Sociales), Paris, France
}

\begin{abstract}
User research has become central in design practice and an increasingly wide range of research tools is now available. In this context, design students need a broad understanding of a variety of user-research methods. Cultural probes (or empathy probes) are a designerly method-set which can represent a valuable learning opportunity. This paper is based on four years of experience of introducing self-reporting tools in the design education context, as well as student and participant feedback on probe design and testing. This tool set encourages designers and design students to approach user-research and increased user involvement as a creative challenge. Effective design of self-reporting tools involves careful adaptation to specific user needs and contexts, generating empathy and understanding. Advantages, challenges and difficulties related probes as design tools and as communication and learning are illustrated. The aim of this paper is to position this family of user research tools and show their particular relevance in the design education context.
\end{abstract}

Keywords: User research methods, design probes, self-reporting, student feedback

\section{INTRODUCTION}

Research into user needs has been part of design methodology for over 60 years [1], but during the last 10 to 15 years the spectrum of approaches for doing user research within design has widened [2]. User research is not only a question of data collection and identifying needs but is also progressively more about user-inspired design [3], about empathy with users and involving them in the design process. Learning about and practicing ethnographic research in the sense of in-situ data collection, is increasingly important [4] in design studies. User research underpins design activity and is thus an essential part of design learning. Equally there is a need to broaden students' vision of what user research is and for them to understand how it is part of all stages of the design process [5]. In this context, the series of research approaches that can be grouped under the umbrella term of probes [6] are a valuable learning opportunity on different levels. This paper contextualises this self-documentation [7] research methodology within user research and highlights some issues relevant to design education. This paper presents findings and reflexions based on four years of teaching experience [8] and student feedback on this subject at different stages of design study, in two different universities.

\section{USER RESEARCH AND PROBES (CONTEXT/PROBLEM)}

Over the last 20 years, user research in design has become more diverse and ambitious in scope. Growing interest in user-centred design has stimulated a shift of focus from users' behaviour to the users' affective experience of human-product interaction [9]. There is an evolution in design activity towards people-centred approaches [10], with more emphasis on inclusivity, empathy and social issues, and research processes that "delve deeply into specific human needs and experiences" [10]. The current design landscape is increasingly multi-disciplinary. It is also important to note that certain user research methods may be closer to (academic) design research while others may be part of design practice. Doing research is a growing part of design education but also designerly ways of doing research are becoming part of wider academic research methods [11]. While relevant to design practice, probes may tend to be seen as a more an "academic" research tool.

With a growing range of user research methods available, thanks to the diversity of theoretical backgrounds influencing current design [9], determining which methods are most relevant to design education is an important point. At issue is both a means to choose which methods need to be part of the 
design curriculum, but also helping students to get a sense of the method landscape. One way of conceptualising different types of user research which has proved useful in the context of design teaching [12], is to consider methods in terms of participant implication. In Table 1. a small selection of user research methods are mapped onto a sliding scale of participant implication in the research. This structure, whilst clearly a simplification, clarifies the main families of research methods. Whilst keeping the emphasis on the participant, this categorisation determines a variety of levels of user participation that students can facilitate and be familiar with. Above all, this framework encourages students to think in terms of (collaborating and communicating with) the participant.

\begin{tabular}{|c|c|c|c|c|}
\hline Observation & Interviews & User-narrated actions & Self-documentation & Generating tools \\
\hline LOOKING & ASKING & TALKING & SELF-REPORTING & CREATING \\
\hline \multicolumn{3}{|l|}{ fly on the wall } & grafitti wall & \multirow{3}{*}{ collage } \\
\hline shadowing & laddering & storytelling & diaries & \\
\hline \multicolumn{2}{|c|}{ controlled observation } & ivate camera conversation & sation & \\
\hline
\end{tabular}

Table 1. categorising methods by participant implication

\subsection{Cultural probes}

"We've brought you a kind of gift...They're a way for us to get to know you better, and for you to get to know us." An assortment of maps, postcards, cameras, and booklets began accumulating in front of them. Curious, they started examining the materials. Soon they were smiling and discussing them with their neighbours." [13] This quote, from the seminal paper by Gaver et al., establishing the concept of probes as a research tool, gives a clear idea of what probes are still about. In addition, probes can be said to be methods involving a) user participation by means of self-documentation, b) studying user's personal context and perceptions, and c) applying exploratory mindsets and materials [7]

Other aspects of cultural probes mentioned in related literature [14] are supporting participant self-reflection, allowing participants to do data collection themselves, enabling research over time, permitting research in multiple locations simultaneously, and requiring fewer resources than other ethnographic approaches. This type of justified but rather pragmatic definition, has needless to say prompted comments on the risk of probes becoming a poor substitute for ethnographic enquiry $[4,6]$. This danger of cultural probes becoming a form of discount ethnography [15] can be set against a key aspect of cultural probes $[6,7,8]$ which is their designerly nature. Cultural probes contain elements with links to other disciplines such as user diaries for example, but are a tool originating in design. They use skills and a mindset that designers possess. They are form of tool that is designed and involves researcher creativity but also encourages creativity on the part of participants. Probes also have a "making" aspect [2], the tool kits themselves are tangible, which supports communication and helps clarifying objectives both for researchers and participants.

Despite the consciously non-scientific approach of the original probes, subsequent researchers have tried to better define the nature of the tools, suggesting that the process should involve five phases [16]; 1) Tuning in to the topic, planning, designing, 2) Probing by users, i.e., self-documentation, 3) First interpretations by designers/ researchers, 4) Deepening together by users and designers, e.g. follow-up interview, 5) Interpretations and outcomes, sense making by designers/ researchers.

In the above descriptions the expression self-documentation is given to explain what probing is. Probes (and probing), whilst now being the recognised names for this family of research tools, are a strange choice of word. The noun form in online dictionaries relates to something that probes, examines or tests, generally a long thin flexible instrument for exploring the body or an unmanned spacecraft [17]. Probing as a verb can also be trying to discover information that people do not want you to know [18]. More evidence of the naming issue can be found in the large number of what have been called ' $x$ ' probes, that is to say methods that replace the 'cultural' of the original version to indicate a different style or variation in topic [6] (Identity probes, Urban probes, Domestic probes...)

Behind the question of a meaningful name lies an ambiguous aspect of probes. They have become a very popular and widely reported research method, but their experimental, uncertain nature leads to many attempts to codify them into easily-reproducible methods or recipes [6]. Probes illustrate the 
difficulties surrounding methods seeming to lack scientific validity [3], but also of questions of closed versus open interpretation [6] and data collection versus a responsive/reflective approach $[6,8]$

\section{TEACHING SELF-REPORTING}

The probe teaching experience supporting this paper is based on two different sources. The primary source of detailed information on introducing and testing probe design with students concerns a workshop format module with final year (5th year) masters students in service and social design over three years. The secondary source is a series of projects, over four years, with freshman and 2nd year product and service design students aimed at enlarging their user-research tool set. In this second case, use of self-reporting approaches was part of a basic design module and was not compulsory.

The master's (M2) workshops took place between 2015 and 2017. The class sizes were between 12 and 15 students. The students worked mainly in groups of two or three for the probe assignment. The cohorts of second year design master's students already had good knowledge of user-research methods but were not familiar with cultural probes before the workshop. The format of the workshops in terms of general content and timing is summarised in Table 2. This gives a simplified over-view of the workshop timing. In practice the three workshops reported here all had very slightly different time-frames, for example slightly longer period between first and second phases of tutoring, and two and a half rather than three days final phase tutoring. The aims of the workshop were described to students as being two-fold: exploring longer user-product relations in the context of sustainable behaviours and experimenting creative user-research tools.

\begin{tabular}{|c|c|c|c|c|c|c|}
\hline DAY 1. & 2. & 3. & & 12. & 13. & 14. \\
\hline $\begin{array}{l}\text { USER RESEARCH } \\
\text { METHODS } \\
\text { SELF-REPORT EX- } \\
\text { ERCISE }\end{array}$ & $\begin{array}{l}\text { READ UP ON } \\
\text { PROBES } \\
\\
\text { START DESIGN- } \\
\text { ING/PLANNING }\end{array}$ & $\begin{array}{c}\text { START TO BUILD } \\
\text { TEST } \\
\text { REBUILD } \\
\text { REFINE }\end{array}$ & $\begin{array}{l}\text { class finalising } \\
\text { kits and self-re- } \\
\text { porting by partici- } \\
\text { pants }\end{array}$ & $\begin{array}{l}\text { DISCOVERY OF MA- } \\
\text { TERIALS } \\
\text { FOLLOW UP INTER- } \\
\text { VIEWS }\end{array}$ & $\begin{array}{l}\text { COMPILING RE- } \\
\text { SULTS } \\
\text { ANALYSING }\end{array}$ & $\begin{array}{l}\text { PRESENT/REPORT } \\
\text { 1) user context re- } \\
\text { search } \\
\text { 2) process/tool in- } \\
\text { sights }\end{array}$ \\
\hline
\end{tabular}

Table 2. Masters workshop planning example (work in class)

The workshops kicked off with a presentation and discussion of user-research methods, and discussion and exercises around the (sustainability) research subject. Students individually completed a personal self-reporting task in their own domestic context between day one and day two. The second day involved discussing findings and observations from the personal task, followed by presentation, reading and discussion of some academic literature on probes, chosen as giving a variety of views on the subject and being accessible [e.g. 13, 20]. Good practice in terms of probe design/ implementation from previous workshops was shared with students. The workshop theme "Using Design/Cultural Probes to gain insights about longer product relations", required student teams to design and test a probe kit with three participants (who needed to be outside of the student cohort), to be left with them for a period of 7 days. From the end of day two, student groups started planning and designing their probe kits, and started to build rough versions of their kits in class on day three. Teams were tutored individually for help designing and planning, but final versions of kits were for the most part completed after day three. Students were encouraged to test their kits and exercises before roll-out, but due to the tight time frame, not all teams were able to do this.

After the probe implementation and self-reporting by participants, findings were shared and discussed in class on day four. Teams who had not completed follow-up interviews were encouraged to do so, and missing participant material was collected. Class discussion highlighted initial surprises, difficulties and observations from the tests. The last two days of the workshop involved analysis of collected materials and creating a detailed report divided into research subject insights and probe tool insights.

Findings presented here are based on class notes by the tutor over the three workshops, on-going group discussion during workshops, oral feedback at the end of the workshops, written reports by student groups including their feedback on the methods and their experience, and finally participant feedback on the probes experience. While students did not complete individual learning diaries during the process [3], but noted their experiences as a group, the student reports on their process do nevertheless give a behind-the-scenes view on their experience. 
The secondary source of probe introduction experience in design education relates to basic design modules between 2016 and 2018 (B1,2). The students involved had less knowledge of user-research methods. Using self-reporting tools in the context of their projects was not mandatory but encouraged. The subjects researched differ from those in the M2 case, some examples are: personal daily commuting experience, personal drinks consumption, drink related waste behaviour, amateur daily running related to weather issues, kitchen sharing in flat shares. Common points between the M2 and B1,2 cohorts are the presentation of user-research methods, discussion of the self-reporting family of tools, students' unfamiliarity with these methods, pinning up and discussion of results, work space configurations that enable work to be viewed, shared and discussed easily and the relatively short time frame for designing, making and implementing the research tools.

\section{A SELECTION OF FINDINGS}

Following both Wallace et al. [8] and Mattelmaki et al. [7], the selection of findings detailed here are divided into two perspectives, which also illustrate two different and important aspects of working with self-reporting tools. Firstly, as a tool designed for entering users' contexts, and secondly as a process of collaborative discovery and learning, including relationship/communication issues.

\subsection{Designing/tools issues}

"The kit's quality, even though it is low tech, gives value to participants. It encourages people to get involved." This M2 team from 2017 designed very simple probe elements, but daily activities were organised into attractively numbered envelopes and the kit was addressed to each participant by name. Probe kits need to be well designed $[8,15]$ and also personalised, and when well-designed give a sense of respect and attention to users [8]. The literature suggests that materials should not be too polished in design, and our findings seem to show that visually simpler but well thought out kits worked better. Some student groups did over-style their probe packages, often without sufficient thinking about user reactions/tasks. Generally, student kits were low tech, both in M2 and B1,2 cases, due to timing and resources, but this also worked better. The few teams who tried more tech-based versions also experienced more failures and difficulties, a point which has been mentioned in the literature [4]. Another issue was media choices not being adapted to participants, which was not a problem in the more lowtech designs.

The tangible, visible nature of probes seems appealing both for designers and participants. For both M2 and B1,2 groups the returned materials were very communicative to the peer group, generating interest in class.

The description "playful" is very widely used in probe related literature, but reactions to this aspect of probes were somewhat ambivalent in work by M2 students. In reaction to the same probe kit, feedback from two different participants included "the activity doesn't seem serious enough" and "the game is fun, I had more pleasure doing it each day". A certain number of participants were not comfortable with the overly jokey atmosphere of the student kits and different participants reacted very differently to the same kit (it should be noted that M2 students were designing for 3 different people). One team commented that it "doesn't work for people who are very rational." Generally participant comments mention that they "found it entertaining and not boring" and it was a "pleasure to answer". The "playful" quality needs to be carefully dosed and should not be seen as a prerequisite probe design style.

General enthusiasm for the probe design exercise was very high amongst M2 students, and teams tried quite a variety of methods, and invented some of their own, for example working on a Tinder-themed probe. Role play, fiction and personification tasks seem to have worked very well with participants not having difficulties doing "fantasy" exercises. Some students successfully included audio recording in their probe tasks, in the form of think aloud protocols. Students were good at and enjoyed the creative challenge.

The amount of time needed for student teams to prepare and make their kits varied widely. One group completed all the work for the assignment only during the 6 (full) days of workshop in class, with successful results. A majority of student teams reported spending three to four days designing and making their kits, but some spent much less, reporting just one and a half days preparing time. These findings seem to suggest that probes can be designed and implemented in quite tight timeframes in the context of design education, but it may nevertheless be useful to allow slightly more time than in our model. This type of tool seems to encourage rethinking time issues in user research. Creative user research can be short but involves shifting the part of the process which demands time. More time designing and 
preparing and thinking about participants is required early on in the design process, but subsequently frees up time for other research activities during self-reporting.

While many of the M2 teams were very creative and inventive in their probe designs, certain teams created probe exercises that were close to questionnaires. Boehner et al [6] mention this as one of the misappropriations of probe methodology. For students who missed part of the workshop, thus receiving less explanation, there was a tendency to lapse into a form of survey, with exercises that were insufficiently open-ended. [6]

Another result from students who received less explanation of probe methods was to take a formatted or off-the-shelf approach, inspired by what had been seen to work for another group/student. This was particularly the case for B1,2 students who were inspired by the success of their colleagues but tended to assume that the format used was "the" format. Encouraging re-design for each new subject and participant group is important.

The amount of information and support in the B1,2 version was clearly not enough. Only by a small number of students used self-reporting tools effectively, but interestingly, those who did use these tools were very enthusiastic about results and their efforts generated emulation in the peer group. The skill set for making meaningful probes does not appear to have been a problem, but grasping the nature of the tool, and making the leap of faith to try it was difficult for the majority of students. This may be in line with findings around failure avoidance in design students. [19]

\subsection{Learning/communication issues}

Probes have been described as allowing a hands-off, unobtrusive form of user research [20]. An aspect of probes mentioned by many students was how participants appreciated both the distance and the time, but also how both parties felt involved. Self-reporting methods require implication and investment from participants, therefore a lot of care and attention for the people involved needs to go into the design process. In one successful case, (M2) students recorded an audio CD for each participant to accompany them during certain tasks. Participants commented very positively on this idea as balancing a need for intimacy and not feeling alone to complete tasks. This form of research is in fact both hands on and hands off - so teaches a form of restraint and care at a distance, and understanding in advance, which gives value to participants

Students commented in their feedback that these methods, (and the M2 research theme), were good for getting to know participants. In many cases the participant responses and uptake surprised the student cohort positively. Exercises they weren't sure of were actually completed well.

Many students, both in M2 and B1,2 understood the need to personalise the probe kits. Students also became aware that some form of thank you gift was good to include in their design. This was picked up on by freshmen (B1) students, despite the short time frame, and generated a lot of peer-group discussion. Encouraging awareness of participant contribution and the need to express gratitude appears to show how the tools helped to generate positive attitudes to people and to communication with them.

Communication within the teams is also a positive outcome that can be identified in the findings. In all cases, work done by teams was more successful than for students working alone. The probe designing process may also generate team building [20].

Another team related insight is that students were able to get very valuable reactions from couples replying to probe kits. The literature mentions cases where probes are discussed by participants [8] with other family members but rather than considering the fact that participants may talk to other people during the process, it seems highly beneficial from student feedback to imagine kits specifically designed to be used by couples.

Mattelmaki et al. describe probing being typically applied in the early phases of the design process [7] whereas Wallace et al. [8] describe their use of probing as a longer communication process with participants, spreading well beyond the initial exploration phase. One student group identified these tools as being relevant as a form of icebreaker to start a relationship with participants, and another group felt the tools would work well as part of many projects to get to know participants better, while several groups mentioned participants expressing keenness to continue the exercise beyond the attributed time. The findings from our research support the idea that these tools can be seen as part of a longer participant relationship and may constitute an element to facilitate this participation.

Although in communication and learning terms the M2 student experiences overall are very positive, with students all commenting they hope to use the methods again, it is important to mention that in each year of M2 workshops, one of the (five to seven) groups completely failed to get meaningful results or 
misinterpreted the exercise. This failure rate is low but should nevertheless be taken into account. It can also be noted that nearly all M2 teams had at least one activity in their kit that didn't work as intended, but this could be seen as useful learning in the context of this methodology.

\section{CONCLUSIONS}

Probes constitute a designerly form of user research that seems to motivate and interest students. Userresearch can be viewed as creativity, and careful design pays off. This tool set is also design-like in the sense of being open-ended and not producing 'one right answer' and is thus useful in the teaching context for showing that not everything "works", and that good design process is not about control.

Probes are particularly valuable learning in the sense that they encourage care and attention to people involved and facilitate non-designer creativity and prolonged participation.

We now, tentatively, suggest a longer list of phases as a guideline for introducing and testing probes in design education, reflecting the need to take more time at the start of the process for careful designing: 1) familiarisation with probe concept, 2) consideration of participants/context, 3) designing, self-testing, re-doing, testing, 4) careful building/making, 5) participant self-documenting, 6) first interpretations, 7) follow-up interview, including participant feedback on process, 8 ) interpretations + outcomes: empathic understanding, descriptions of users and their contexts, ongoing communication, co-design 9) reflection on probe process from student designer/researcher viewpoint.

In conclusion, designing and testing self-reporting tools can be a valuable learning exercise, treated outside of a project, and even in quite a short timeframe. Encouraging probe use can be highly relevant in design education, encouraging students away from recipes and easy solutions and towards deeper user understanding, empathy and creativity.

\section{REFERENCES}

[1] Dreyfuss H. Designing for People, 1955.

[2] Sanders and Stappers, Probes, toolkits and prototypes: three approaches to making in codesigning, in CoDesign, Vol.10 No1,5-14, 2014.

[3] Lee J. The True Benefits of Designing Design Methods. Artefact, 2014, Volume III, Issue 2.

[4] Sobolewska E., Smith C. and Turner P. Auto-Ethnography: Problems, Pitfalls and Promise. In HCI Educators: Playing with our Education, 2009.

[5] Hannington B. Generative Research in Design Education, In IASDR 07, Hong Kong 2007.

[6] Boehner K., Vertesi J., Sengers P. and Dourish P. How HCI Interprets the Probes, In Proc. CHI 2007, ACM Press, pp. 1077 - 1086, 2007.

[7] Mattelmaki T., Lucero A. and Lee J. Probing - Two Perspectives to Participation, in P. Markopoulos et al. (eds). Collaboration in Creative Design, Springer Switzerland, 2016.

[8] Wallace J., McCarthy J., Wright P. and Olivier P. Making design probes work, In Proc. SIGCHI, Conference on Human Factors in Computing Systems, ACM Press, pp. 3441-3450, 2013.

[9] Desmet P. and Hekkert P. Framework of Product Experience, I.J.D., 1 (1) 2007.

[10] Myerson J. Scaling Down: Why Designers Need To Reverse Their Thinking, E\&PDE 18: https://www.sciencedirect.com/science/article/pii/S2405872617300552 (accessed 26,11,2018).

[11] Stappers P.J. and Sleeswijk Visser F. Meta-levels in design research: Resolving some confusions. In Proc. DRS 2014, Umea, Sweden 2014.

[12] Green C. Ethnography and Design, Understanding Everyday User-product Relationships, In $E \& P D E$, Dublin Institute of Technology, Dublin, Ireland, 2013.

[13] Gaver B., Dunne T. and Pacenti E. Cultural Probes, In Interactions, Jan/Feb 1999.

[14] Elizondo G. Designing for sustainable behaviour in cross-cultural contexts: a design framework, $\mathrm{PhD}$, Loughborough, 2011.

[15] Thoring K., Luippold C. and Mueller R. Opening the Cultural Probes Box: A Critical Reflection and Analysis of the Cultural Probes Method, IASDR, 2013.

[16] Mattelmaki T. Design Probes, University of Helsinki, www.uiah.fi/publications, 2006.

[17] https://www.collinsdictionary.com/dictionary/english/probe, (accessed 04,03,19).

[18] https://dictionary.cambridge.org/dictionary/english/probe, (accessed 04,03,19).

[19] McCardle J. Performance Metrics: Are the risks too high to be creative? In E\&PDE, UK, 2018.

[20] Crabtree A et al. Designing with Care: Adapting Cultural Probes to Inform Design in Sensitive Settings, In Proceedings of OzCHI, 2003, p4-13, Brisbane, Australia. 